\title{
The Role of the Virtual City in Urban Development
}

\author{
Hasanain A. Karbol*, Sarah M. Al-Saadi \\ Department of Architecture, Faculty of Engineering, University of Kufa, Najaf, Iraq
}

Corresponding Author Email: hasanaina.karbol@uokufa.edu.iq

https://doi.org/10.18280/ijsdp.160717

Received: 24 August 2021

Accepted: 10 October 2021

\section{Keywords:}

virtual city, virtual architecture historical identity, virtuality, virtual heritage, information city, traditional cities, urban development

\begin{abstract}
The virtual reality of cities is the current historical period of urban progress and a kind of interconnected co-activity between innovative virtual elements, elements of the city and its urban parts according to the affected relationships of social, financial, cultural, spatial, political and local features. Where contemporary concepts of virtual reality were presented by the philosophical corps without clarifying their role comprehensively in the urban development processes of cities, so the research aimed to determine the roles of the ideas of the virtual world and the virtual city in the work of both specialists and decision makers, and the urban development processes of traditional and historical cities, where the research information methodology compares theoretical architectural and urban models to intersect with the basic concepts related to the virtual city, the research reached multi-level roles in terms of impact and degrees of complexity, which contribute to an innovative reproduction of urban development processes.
\end{abstract}

\section{INTRODUCTION}

The development of virtual reality for city models is a cutting-edge idea that is being adopted by the rapid advancement of computer capabilities. Such models are now being created by a group of city authorities, researchers and developers [1]. Concepts of this emerging reality include the idea of simply innovating through "innovation in action" [2] and "successful new ideas" [3]. These short definitions generally emphasize not only a new idea but a new practice. The virtual city refers to innovation in dealing with urban problems in traditional cities [4]. The new product can be innovative through product making, process (new ways of designing and reorganizing), attitude (new contexts), strategy (new goals or objectives), and rhetoric (new language and new concepts) [5]. Accordingly, many cities around the world have used three-dimensional (3D) computer demonstrations. 3D material modeling is still used in many cases as a flexible way to display the results of the latest advances within the urban fabric by collecting 2D material models and plans, rendering drawings, composites etc. to present a visualization of complex urban architecture [6].

It is undeniable that virtual architecture has a research perspective; Some might say a vision for the future: understanding the logic that our future societies will follow, the problems that future manufacturers will have to tackle...etc. Moreover, virtual architecture shows an innovative futuristic vision for thinkers, artists, architects and urbanists to offer a variety of innovative solutions. The virtual city is an innovative tool for thinking and metaphor of the physical city according to a correct understanding of the historical symbols and historical identity that distinguish any city from another, where each city corresponds to the region and the country, by date and country, cultural dimensions. Therefore, the special environment of each city will be different from the traditional environment of other cities [7].

From this point of view, the research problem can be formulated in investigating the role of the concepts of the virtual city in embodying the city's symbols and historical landmarks within the modern technological dimensions, and defining the research objectives:

(1) Clarify the role of virtual reality in creating effective communication between various academics, stakeholders and specialists in design and planning.

(2) Defining the roles of the virtual city in revitalizing and developing the city's heritage fabric.

\section{RESEARCH METHODOLOGY}

The research methodology is based on a sequential process, each stage linked to the previous one, and the steps of the sequence are as follows:

(1) Establishing a knowledge base by presenting the most important studies and previous literature that dealt with the subject of virtual reality, virtual architecture and virtual cities, and how to invest them.

(2) Analyzing the theoretical research information to build a theoretical base through the intersection of the basic concepts related to the virtual city and the traditional city and the ways of investing them in urban development processes.

(3) Analysing a number of global architectural models, leading to defining the roles of virtual cities in the urban development of the traditional city.

(4) Conclusions and future prospects of the research. 


\section{DEFINITION RELATED TO VIRTUAL CITY}

Virtual City can be defined as Reconnection for all realistic urban elements and imagines within the virtual space. On the other hand, it is the "interactive simulation and virtual environmental analysis for the planning of real urban spaces" [8].

Even though a virtual city can possess a practically endless number of explanations, in this study, it is assumed that virtual reality of city represents the merge of items exactly linked to Information and Communication Technologies (ICTs), in terms of their relationships with cities. These are, in turn, fundamentally linked to the 'conventional' city concept through what is so-called cooperative / recombinant/ cybernetic urbanization. It is said that virtual reality of city is not a portal of website on the web, nor does it is a contemporary city as an entire. It is often thought to be rather in between. The modern organization of urban spaces embraces virtual cities, but it isn't limited to them. The outcome is often a 'hybrid' city (Castells' informational city), in which, the innovative and conventional items coincide in a complicated interface of flows (space of flows), electronic and physical spaces. Virtual cities are thought to be within the range of this research as a conjunction of virtual demonstrations, physical exhibitions and social interactions exactly associated with the advance of ICTs in cities. According to this idea, there is a trend of reassembling and cooperation which interacts with the virtual reality and thus the physical modelling of cities. Yet, from the aim of view of designing and governance, it is believed that this method of intermingling is often consciously affected by policies and methods. This is often because of the possible influence of rules and public strategies to form the method of ICTs are ordered and applied within the urban milieu [9].

Figure 1 shows that if virtual cities can be recognized and understood with the same depth as they are understood in several features of conventional cities, then there will be an ability to comprehend a significance component that constitutes the information age city (Castells [10] "Media City").

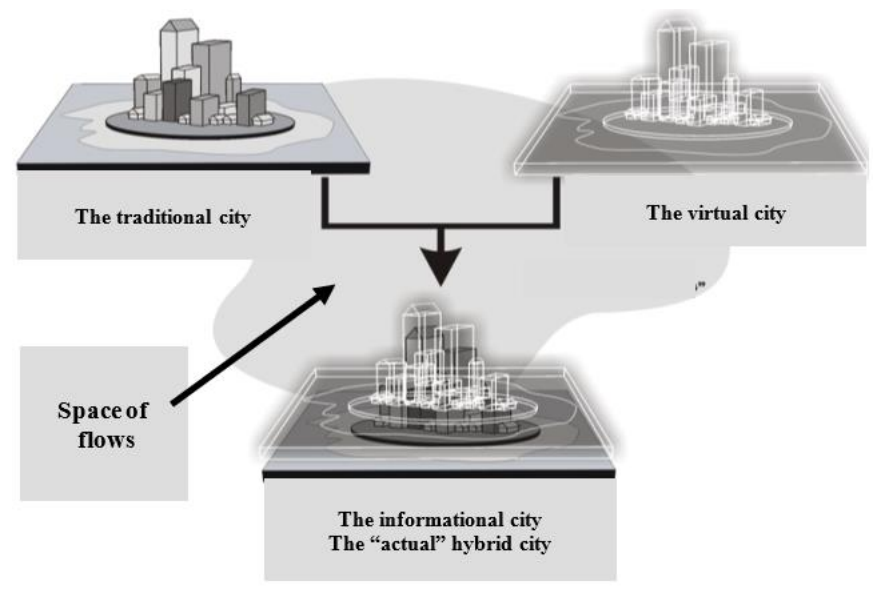

Figure 1. Virtual cities as part of contemporary cities

Castells [10] defined a total range of societal and financial changes, caused by the emergence and introduction of innovative technologies into many sides of our daily lives. The author explained these influences to say that amongst various spatial influences such as dispersion and real-time spatial focus, the information age heralds a innovative urban form, the "information city." The virtual reality of city (the city of ICTs) is an essential fraction of the information city of Castells, but alongside with the 'space of flows' or the "physical organization of time, the exchange of social practices that operate through the flows."

Therefore, the virtual reality of city operates and interacts with the space of flows and conventional structures of the conventional city to conclusively make the information city (hybrid city) [10].

Virtual reality has been getting a huge publicity over the previous years. Its interactive, active and increasingly experiential features had led VR to mimic real worlds with varying levels of realism. Regenbrecht \& Donath (1997) have described it as "the component of communication which takes place in a computer-generated synthetic space and embeds human as an integral part of the system...". The constituents of a virtual reality technique comprise effects, application, reality simulator and geometry. The building of the virtual reality environment is in three main stages: modelling, rendering, and real-time cooperating display utilizing the system effect [11].

\section{THE VIRTUAL ARCHITECTURE IN THE CITY}

The digital revolution of the last century has involved a large number of sectors such as, information, communication, engineering, transportation, etc., which proves the scale and importance of this technological innovation. From this logic, the architectural world, both in design and in perception, was affected by computer-intervention in the working stages from the initial stages of ideas to negotiation, the research stage to the projection stage, and even in the realization of the site, the digital tool undoubtedly invaded all stages of the project. Architectural application, whether through computergenerated 3D models using AutoCAD software or images hung on barriers that prevent access to the site [12].

A simple subtle look at what could be and is still today the city's virtual architecture makes it possible to realize the formal volume that can conduct this specific type of spatial perception, without much difficulty. On this point, the computer program came to constitute a real depth of virtualization that had, until then, been relevant only to a dream among "pre-digital" architects. Indeed, the possibility today afforded to the power of imagination of walking and enjoying the smallest details of a building that does not exist may greatly disturb the approach in which the architect, just like the visitor, can feel through browsing these atypical places [13].

However, even if it is true that the computer has allowed a significant acceleration of virtualization in architecture, the latter did not discover it with the advent of computing. Since we have already managed to get close to the bottom line, virtual architecture in the city is not a new phenomenon, which is also why we will talk here about virtual architecture instead of digital architecture [14].

\section{STUDIES ABOUT VIRTUAL CITIES AND URBAN DEVELOPMENT OF TRADITIONAL CITIES}

\subsection{Previous studies}

The significance of $3 \mathrm{D}$ reconstruction of structures, cities 
and urban landscapes is increasingly recognized. Computer applications in urban planning and design is extensively used in several interrelated aspects of research like agent-based modelling, transport modeling, Geographical Information Systems (GIS), planning, public association, decision making, urban morphology, spatial analysis, etc. Virtual City Models (VCM) propose architects, city planners and investors a future-oriented digital means. Visualizing complicated urban architecture in virtual reality demonstrates may be a novel way of design and presentation. The joystick permits the viewer to fly within the 3D model in real-time and have a glance from various perspectives at complex topographic structures in addition to the smallest architectural details [13].

Numerous cities around the world are utilizing the real time technology in virtual reality to strengthen making of decision during the design, planning and management activities of urban systems. Lots of studies have been done dealing with 3D city demonstrations [15].

\subsubsection{Elmira Jamei \& other}

The advent of ICT and virtual reality is helping city planners visualize big data. Indeed, visualization in virtual reality of cities has facilitated to conduct a variety of matters concerning sustainable advancement from a new perception. Virtual reality permits investigators to accomplish a real-time examination of various "what-if" scenarios and benefits stakeholders, governments, and societies to realize the social and environmental influences of their decisions. Virtual reality applies great influences on urban design in the future, in particular, the design of smart cities. The utilization of Internet-based virtual reality improves communal contribution in design and planning. Moreover, it offers a platform for planners to promote a project irrespective of their place. The significant point includes the ability to fully immerse in VEs that closely embody real-world systems utilizing PBR tools. This characteristic permits normal interface methods to quickly access essential data layers whereas view previously acquired imitation data in real-time for a particular time, navigating VEs and retrieve various camera angles utilizing custom shaders, like infrared and thermal data. The main advantages of utilizing virtual reality to design smarter cities involve [16]:

(1) The ability to evaluate design thoughts in a threedimensional space and in real-time during the planning and design phases.

(2) The efficient interaction between various academics, stakeholders, planning professionals and communities.

(3) Saves a great deal of time by eliminating estimation in design.

(4) The combination of all features into the design, hence, attaining a flexible and ecological city design with the minimum amount of time/money by envisioning the thermal comfort of pedestrians and envisioning the cognitive performance of city dwellers.

(5) Strengthening participatory planning.

\subsubsection{Margaret Horne \& Emine Mine Thompson}

The invention of the virtual city demonstrates is an evolving concept driven by the quick progress of computer programming. Such demonstrations are now being created by a group of city authorities, developers and researchers. Representing the urban system, from medieval aerial view photogrammetry to more precise renaissance city map projections, to productive, standardized, inexpensive and printed 2D maps of the 19th century is not a new issue. However, 3D city demonstrations have been firmly emerging over the past 40 years due to the progress of appropriate hardware platforms and correct quick modeling techniques. The rendering of computer-aided design (CAD) and 3D presentation is nowadays determining the way our cities are created and simulated. However, city demonstrations are not final outcomes, just like their real-life counterparts. With the ever-developing and changing arrangements, legislation, styles, and desires of citizens, the need for city simulation for an energetic and adaptable platform, where such alterations can be easily made, is growing.

Urban planners and designers state that a $3 \mathrm{D}$ computer demonstration is currently a crucial means when respecting complex cityscapes and planning subjects (HORNE 2005), and they distinguish the demand for a flexible means to create 3D blueprints, and to contextualize future developments, such as that of landscapes and public spaces.

Numerous cities around the world are using real-time virtual reality techniques to maintain the process of decision-making during the design, planning and management of urban systems Lots of studies have been done on 3D city models [1].

\subsubsection{Gaitatzes \& Christopoulos \& Rousso}

Heritage is one of the most significant resources that characterizes historical cities, and therefore, virtual reality has offered inventive ways to maintain and document it through the virtual heritage and the transformation of physical heritage to a numerical copy utilizing computer graphics techniques to generate models that permit a convinced level of interface and participation by the consumer. To attain an effective visualization of a heritage building or site, two urgencies must be achieved: Accuracy of demonstration and precision of information. Normally, virtual heritage projects begin by studying pre-completed graphic demonstrations of the location and then use GPS, photogrammetry, laser scanning and traditional survey techniques to finalize the whole drawing of the site. The virtual reality of the city project plans to replace the role of a consumer from being a simple viewer of the prospect to interrelating with the location simultaneously at the virtual sight. The feeling of interactivity is realized by refining the sounds and image utilized in the formation of the virtual reality of heritage, which is powerfully embodied in the improved form of reality projects. The Virtual city task is aiming to switch the customer from being a mere viewer of the sight to cooperating with the site in a manner that makes him believe that he is present in the place and time of the virtual sight. The feeling of interactivity is achieved by boosting the sound and image utilized in the creation of the virtual reality of heritage, which is deeply embodied in the augmented form of reality schemes. The virtual reality of heritage sites could be helpful to customers in numerous ways [7]:

(1) It involves the customer in a way that enhances their feeling of belonging to the location.

(2) It accurately offers information to the customer through listening, seeing and interrelating.

(3) It allows access to a site that no longer exists which could not be done otherwise and offers various views of the scene according to the customer's viewpoint.

\subsubsection{Van D. Anke}

Virtual reality can be used through the entire urban process, with different goals and benefits in several stages, Virtual reality can be useful in various ways in the design, whereby it 
can support the traditional plans and can replace scale models. Starting from the schematic development stage, where there are only rudimentary shapes to show the concept and see how it fits in the existing environment Next, there is the design development where virtual reality helps to give a good idea of scale, order and proportions. Virtual reality can also help in the permit application stage and help in the testing and evaluation phase, before bringing it to reality. Computer simulation for traffic is a good way to experiment with different algorithms in different traffic situations in a safe way. Virtual reality can help in the visualization of transportation, the modelling and simulation of new traffic systems and has many options for driving simulators. In VR, it becomes possible to see the interaction between the traffic model and the environment. When extra aspects of the environment are added, such as wind and number of lanes, it will give a lot of information about the driving speed and time. VR also has a function in the construction stage of the project. When problems arise, it can help to see how to tackle them. A big advantage is the possibility to look from perspectives that are difficult or impossible to see in real life, also in terms of communication with the workers on site, it offers a great value. Whereas in the traditional way only information was exchanged based on CAD plans and verbal information, VR can create a clearer picture. If the VR-model is enriched with the aspect of time and information about the construction and costs, it can be used to make a good planning and to follow up the whole process [17].

\subsection{Studies analysis}

Previous studies can be summarized in Table 1:

Table 1. Information obtained from previous studies

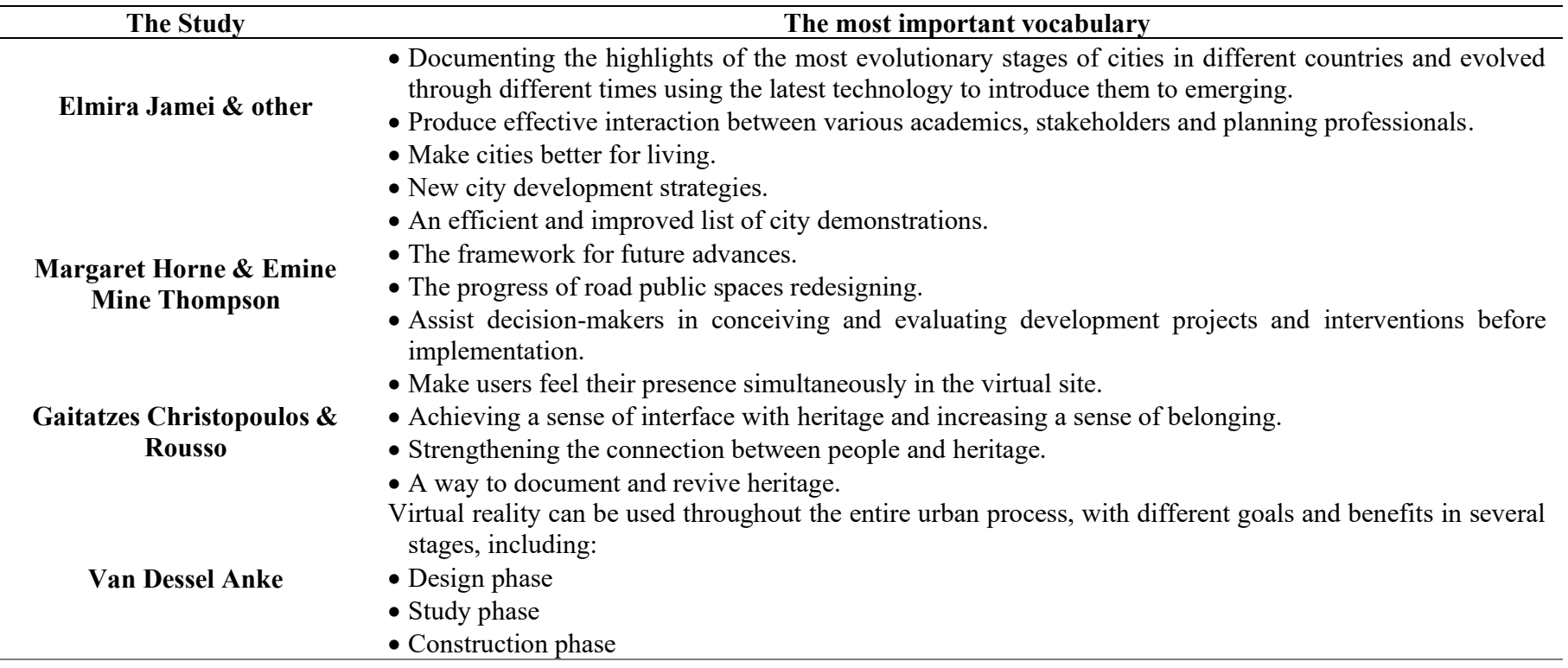

\section{CHARACTERISTICS}

As explained in the previous section, although a virtual reality of city could have an endless number of explanations, it could be thought for the reasons of this research that a virtual reality of city denotes the set of features that are directly linked to ICT, in terms of their relationships with cities. These, in turn, are intrinsically linked to the traditional city through what is called a symbiotic/combined/electronic urbanization [8].

For this study, a virtual reality of city is:

(1) The contemporary organization of urban spaces includes virtual cities to produce a mixed city, where new and traditional elements coincide in a complex interface of flows (space of flows), electronic and physical spaces.

(2) Virtual reality can be used through the entire urban process, with different goals and benefits in several stages, including: Design stage, study stage and selection of the best alternative, implementation and construction stage.

(3) Based on VR technologies that allow the user to navigate virtually inside their streets and buildings.

(4) The most professional real cities serve other parties such as the state and the private sector and are often not available on the internet.

(5) Virtual cities provide true realism for a specific urban space, richness in geo-referenced information content, and the ability to support social interaction with all urban parties in the process of decision-making.

(6) It also permits the discovery of alternative urban planning scenarios, whether for cities or specific regions in them.

(7) It is a major tool for urban planning and management.

\section{EXAMPLES AND PROJECTS OF VIRTUAL CITIES}

In this part, we will review and analyze several examples and projects of virtual cities with the aim of identifying the most important roles of virtual world applications in the architectural design and urban development processes of traditional cities.

\subsection{The particular case asymptote}

To this extent, asymptote represents this architecture Hybrid digital, halfway between virtuality and reality. This architectural agency was created in New York by Lise-Anne Couture and Hani Rashid, particularly known for its arts facilities and its research focused on digital tools of architectural design. With asymptote, architecture is no longer 
solely oriented and reflected on finite space and static geometric: it acquires a temporary, evolutionary, fluid dimension and direct relationship between technology and media. There is thus a redefinition of the architectural work as an infinite object, in perpetual construction and reorientation to other possibilities, to other possible worlds. Asymptote can be defined also as: A mathematical term designating a straight line such that the distance from a point of a curve to these right approaches zero when the point moves away from infinity on the curve. It has been adopted for its philosophical implications reflecting the way of architectural thinking as a trajectory mixing theory and practice. At the origin of projects, mixing the building with an active digital reality, asymptote crosses a considerable step in the virtualization of architecture, so that it writes a new report in the realities that can now be put on a building. The projects of the Virtual NYSE (New York Stock Exchange) from New York and The Virtual Guggenheim Museum strongly demonstrates the extent of these current possibilities [18], as shown in Figure 2.

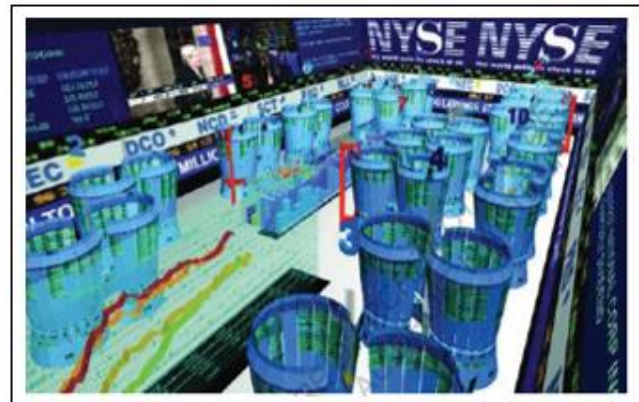

(a) Virtual NYSE New York Stock Exchange.

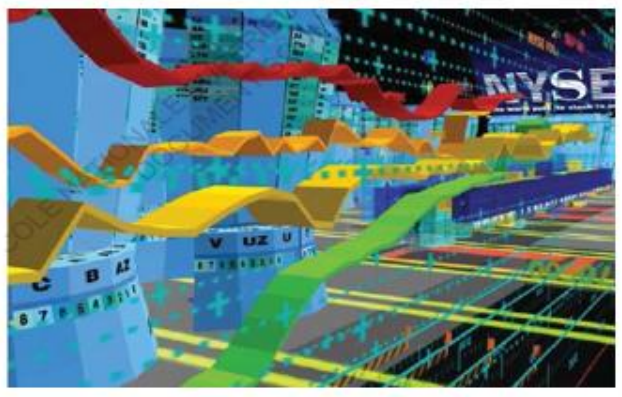

(b) Virtual NYSE New York Stock Exchange.

Figure 2. The virtual Guggenheim museum

\subsection{The FHW Greece VR museum}

Greece began to suffer from a lack of visitors to the museum, and therefore, it chose to design virtual reality of heritage to inspire residents to visit the museum. Accordingly, several different advantages and challenges have been identified. The Foundation of the Hellenic World (FHW) has had an important function in broadcasting the thought of virtual heritage by creating a council for professional urban planners and architects to share their information about Greek cultural heritage and its related visualization data. Greece has set up a virtual reality department to start its education and demonstration project within an advanced environment to improve its infrastructure and create a cooperative foundation between it and other institutes. To realize its objectives, FHW has opened two 10-20-minute virtual exhibitions in present museums. The first project accepted about 5,000 visitors per day, and the second accepted about 100,000 visitors for the duration of the demonstration. Contributors can discover the city by visiting the architectural locations and diving to see the ancient sunken city in the harbor [19].

During their investigation, visitors can see their surroundings from various views and sense proportion, view architectural details and experience the size and features of the spaces created by their ancestors, see Figure 3.

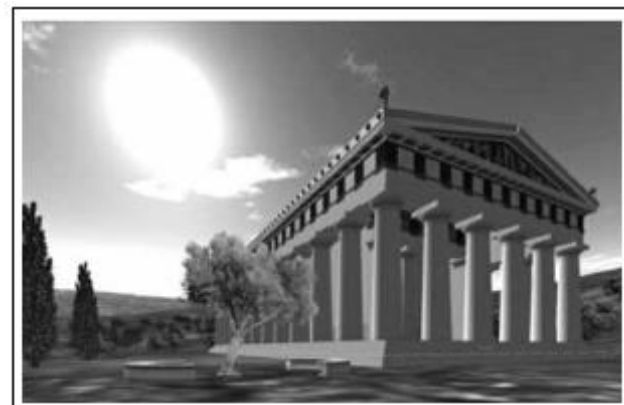

(a) Parthenon temple in Greece Vr

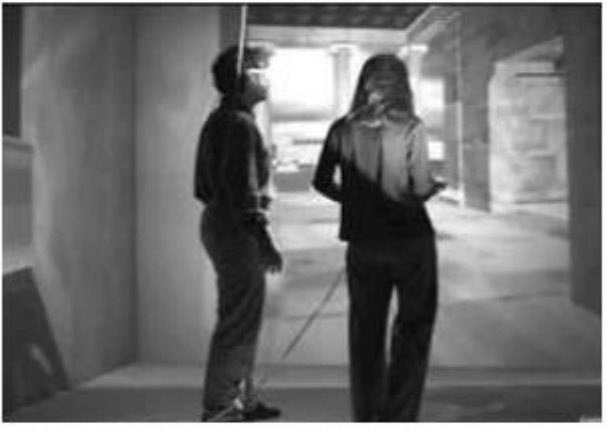

(b) The Greece Virtual Museum Environment

Figure 3. The (FHW) Greece VR museum

\subsection{Newcastle upon Tyne visualisation project}

The project of building a virtual model of Newcastle began as an experimentation to develop a previously advanced virtual model of the North Umbria University campus to a broader area of the city of Newcastle upon Tyne in the United Kingdom. This experimentation was set up to indicate the tight correlation between the campus and the city, in addition to the campus approaches and the city's major landmarks. The primary purpose to create the city-campus model was to advance and demonstrate the close physical connections between the campus and the city in a virtual reality model. The virtual reality model of the North Umbria University City Campus has generated great attention from staff and students alike and has been utilized for several reasons of teaching, learning and research in the School of Built Environment [20]. see Figure 4.

\subsection{Virtual city project of Lyon}

City Team's study interest is centered on the field of engineering modelling and data science, with a line that has regularly led to collaborations with several disciplines (astrophysicists, urban planners, historians, paleoanthropologists, geographers, etc.). Therefore, the project in recent years has been directed on illustration patterns and city dynamics. This topic leads to the proposal of new algorithms for data processing and allows for a better understanding of the region and its developments. The data is 
geometric (generally three-dimensional) and has relevant semantics and topology. It often indicates when and where it will evolve (quickly with sensor data, but also over long periods as city buildings evolve, for example). Performing studies in a virtual environment requires realistic simulation of the relevant objects in order to obtain a good correlation between the virtual environment and reality [20].

The processes proposed here are based on spatial and temporal dimensions, but also objective ones, and should allow for enhanced data exchange in an interoperable manner. The standardization processes in which we participate, for example within consortia such as the Open Geospatial Consortium (OGC), allow the creation of new standards, see Figure 4. The applications of the virtual city in the project provided the possibility of manipulating the patterns of representation and dynamics of the city to suit the project and studying the consequent treatments in the spatial and temporal dimension, leading to an adaptable urban environment and development according to new standards [21].

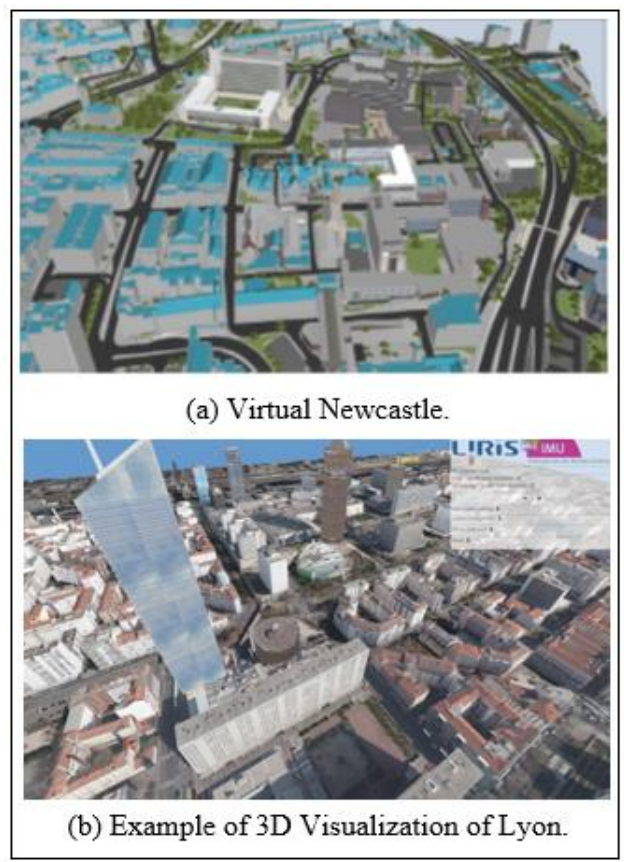

Figure 4. Virtual architecture and contemporary digital project

\subsection{The project of virtual cities}

The Virtual Cities project utilizes 3D modelling software to display lost historical urban landscapes, along with relevant historical information. Utilizing the editing tools panel, users can generate their 3D cities and associate both images and text with landscape attributes. The project implemented numeral technologies before settling on Google Earth, the Google Earth plug-in, toolset, and related libraries, allowing the focus to shift away from implementation to developing a database of historical information and 3D models. The following images were taken from working models such as those in St. Louis neighborhoods [22], see Figure 5.

\subsection{Virtual city of Zurich}

Virtual Zurich unseals a window (viewer) on the digital twin. The viewer aims to enable the visualization of $3 \mathrm{D}$ elements. At some point, 3D models can be displayed and used reactively in Intra- and the Internet via the web interface [23], see Figure 6.

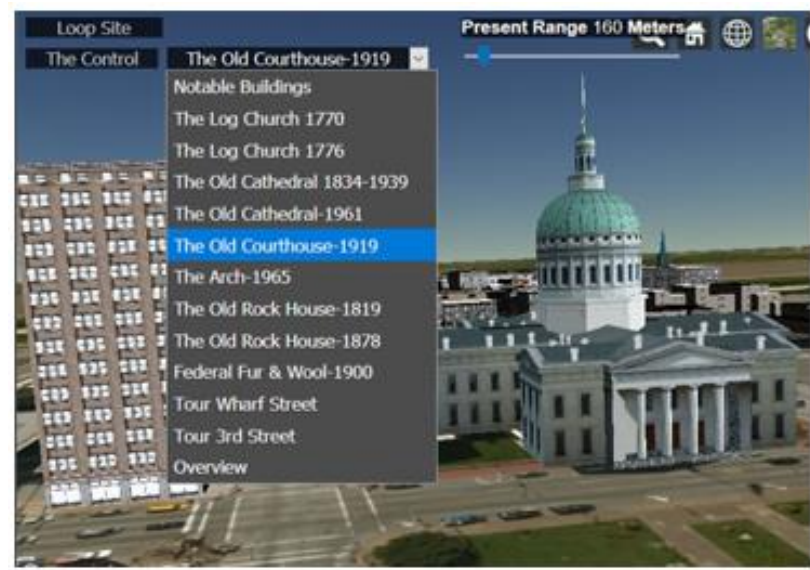

Figure 5. An image showing the way to navigate the virtual city

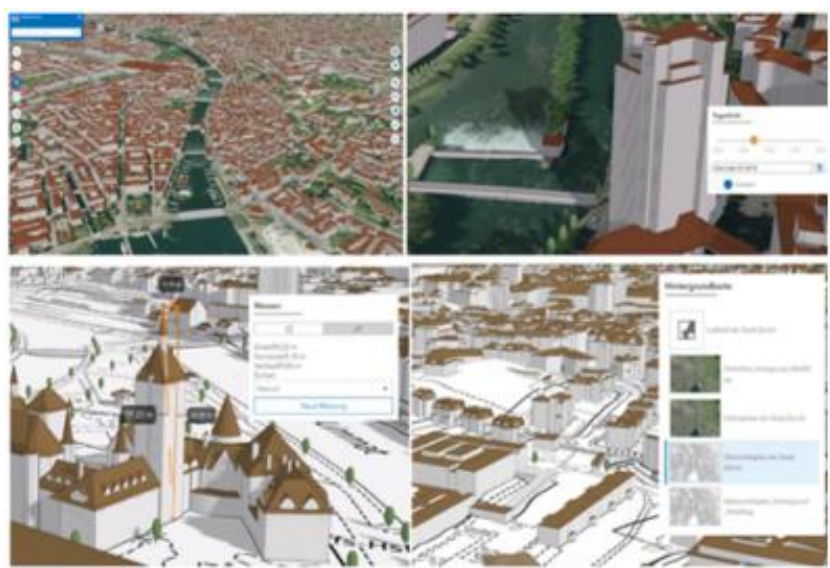

Figure 6. Virtual City of Zurich: Review of the innovative window on the digital twin

The typical results of the 3D virtual city modelling are by entering: Query image, Aerial view, Mid-level display and Street View for virtual cities [24], as in Figure 7. 3D virtual demonstration results example: Column 1 represents the input images, column 2 represents aerial view, column 3 is the midlevel view, and column 4 is the road view of virtual cities.

The necessities of the GIS City of Zurich are included in the application. Along with public access, there will also be private rooms. These private rooms can be utilized, for example, to visualize construction projects and make them accessible to a select group of people [23].

\subsection{Virtual Helsinki platform}

Virtual Helsinki is a digital twin of Helsinki that has been created by means of 3D modelling. The aim is to profile Helsinki as a centre of VR/AR expertise, as well as to attract a million virtual visitors to Helsinki in 2019. The project relied on the concept of virtual tourism, being a pioneering city in adopting the latest digital innovation. Helsinki wants to offer visitors more impressive experiences. The virtual city experience offers unlimited opportunities to visit Helsinki from the comfort of one's own sofa. VR-Helsinki can also be used to promote Helsinki as a host city for congresses and events [25], as in Figure 8 

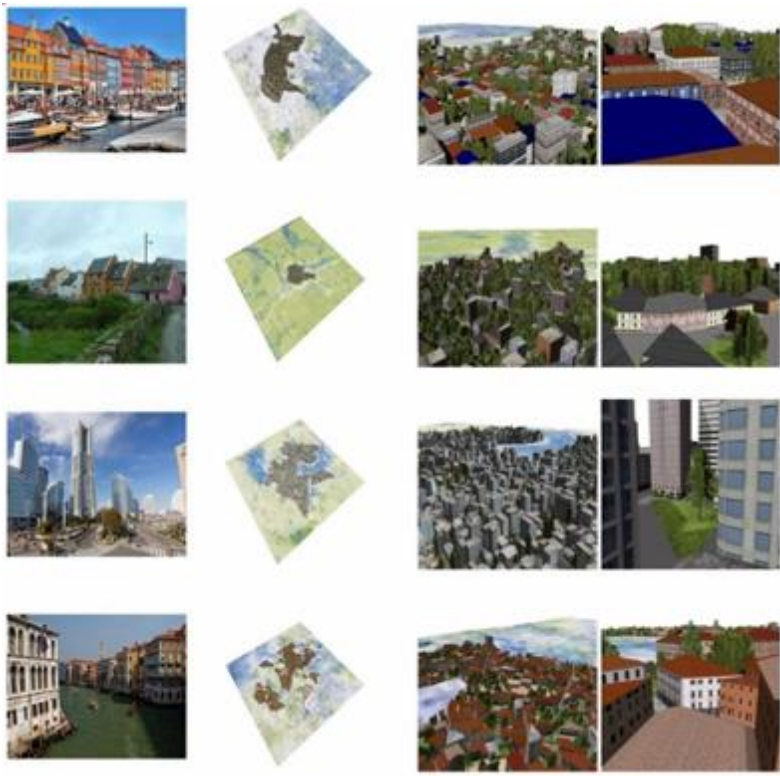

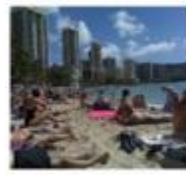

1

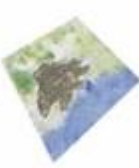

2
3

4

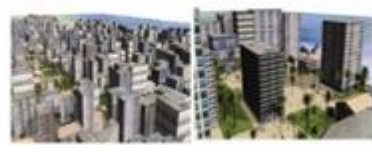

Figure 7. 3D virtual demonstration results example

The project aims to enhance the concept of the city's brand, through a set of procedures used to build a positive image of the city and communicate it through visual images and events locally and globally to obtain a competitive advantage compared to other cities and marketing and development to increase its awareness and attractiveness [26].

360-degree videos are used as a marketing tool by many destinations, Virtual Helsinki goes a step further, allowing visitors to move about freely in the digital simulation of Helsinki to explore at their own pace and create their own experiences in past, present and future time. Virtual Helsinki is a major initiative forming one part of the City of Helsinki's overarching digital strategy, which sets ambitions for the city to become the virtual capital of the world. The initiative is the culmination of a longstanding partnership with Helsinki-based studio Zoan. A digital twin of Helsinki has been built in Unreal Engine using 3D modelling from open data provided by the city, Zoan merged this with a series of drawings, hand-crafted modelling and imagery to create one of the world's most realistic VR experiences. Zoan was awarded second prize at the 2019 Unreal Awards: Experience Design for the design of Virtual Helsinki [27].

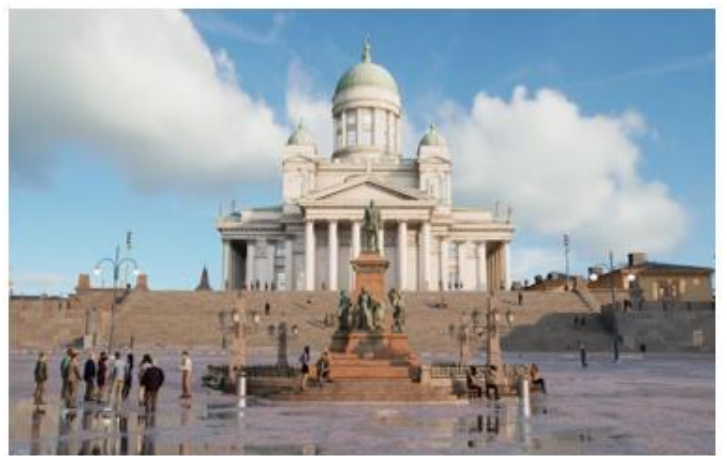

Figure 8. Virtual Helsinki platform

\section{DISCUSSION}

From the above review of examples and projects for virtual cities in this part, we find the multiple levels of innovative roles to virtual reality applications in urban development processes, as shown in the Table 2.

Table 2. Innovative roles of virtual cities

\begin{tabular}{|c|c|c|}
\hline No & The project & Innovative roles \\
\hline 1 & The Particular & - $\quad$ Redefining architecture as a productive, flexible, evaluative process beyond discretion, with \\
\hline 2 & $\begin{array}{l}\text { The FHW Greece VR } \\
\text { Musuem }\end{array}$ & Developing the reality of virtual heritage and thus reviving the real heritage of the city. \\
\hline 3 & $\begin{array}{l}\text { Newcastle upon } \\
\text { TyneVisualisation Project }\end{array}$ & Achieving the close connection between the main city elements and the virtual city model. \\
\hline 4 & Virtual City Project of Lyon & $\begin{array}{l}\text { Presented a proposal for new algorithms for data processing that allow a better understanding of } \\
\text { the region and its developments. } \\
\text { provided the possibility to manipulate the patterns of representation and dynamics of the city. } \\
\text { Analyzing the spatial and temporal dimensions to produce an adaptable urban environment and } \\
\text { develop according to new standards. }\end{array}$ \\
\hline 5 & The Project of Virtual Cities & $\begin{array}{l}\text { Using 3D modeling software to display lost historical urban landscapes, along with relevant } \\
\text { historical information. }\end{array}$ \\
\hline 6 & Virtual City of Zurich & $\begin{array}{l}\text { Designers use a window (viewer) on the digital twin, with the aim of enabling them to visualize } \\
\text { 3D elements, and use them interactively via the web interface. }\end{array}$ \\
\hline 7 & Virtual Helsinki platform & $\begin{array}{l}\text { Enhance the concept of the city's brand, through a set of procedures used to build a positive image } \\
\text { of the city and communicate it through visual images and events locally and globally. }\end{array}$ \\
\hline
\end{tabular}

Through the passage of the research in its successive steps, which were developed as a methodology and analysis of previous studies and practical examples that dealt with the role of virtual city applications in architectural and urban development processes, the research found that the role of virtual reality representation ranges in several levels of complexity from simple too complex to serve many goals that start From educational purposes, architectural representation and presentation, such as virtual heritage, to even the most complex levels, with the aim of developing historical and traditional environments. Which leads to an integration between the physical urban environment and the virtual environment, in the form of an information city with characteristics that enhance the values of both the heritage and 
traditional assets of the city, and draw future, adaptive and contemporary development boundaries, as well as strengthening the community's connection with its ancient heritage and spatial identity.

\section{CONCLUSION}

Virtual cities can be considered an innovative tool and a modern development interface that serves urban design, planning, development and urban management as a basis for urban analysis and simulation by producing proactive threedimensional models of cities and urban projects, which helps designers, specialists and decision makers in the early stages in analyzing and evaluating development interventions before implementing them, which reduces the pros and cons of the projects. Virtual reality can also be considered as one of the necessities in the processes of reviving the city's heritage fabric because it is a basic source of ideas and inspiration from heritage and integration with the dilapidated physical reality effectively and quickly according to transforming the capabilities of virtual and augmented reality into innovative strategies and mechanisms with the aim of protecting and preserving cultural heritage, either through digital recovery For lost cultural assets or by reconstructing hybrid worlds that combine the characteristics of both virtual reality and those of traditional cities.

The research can open future prospects related to the development of urban city elements (nodes, landmarks and axes) in traditional environments, by finding strategies capable of creating dynamic means, complementing human capabilities, and providing them with multiple hypothetical scenarios, improving the quality of urban development processes in the future.

\section{REFERENCES}

[1] Morton, P.J., Horne, M., Dalton, R., Thompson, E.M. (2007). Virtual City Models: Avoidance of Obsolescence. North Umbria University, United Kingdom.

[2] Altschuler, A., Zegans, M. (1997). Innovation and public management: Notes from the state house and city hall. In A. Althschuler \& R. Behn (Eds.), Innovation in American Government, Washington, DC: Brookings Institution.

[3] Mulgan, G., Albury, D. (2003). Innovations in the Public Sector. London: Cabinet Office.

[4] Caragliu, A., Del Bo, C., Nijkamp, P. (2009). Smart cities in Europe. Journal of Urban Technology, 18(2): 65-82. https://doi.org/10.1080/10630732.2011.601117

[5] Adams, E., Koutsomarkou, J., Moulin, E. (2015). Social Innovation in Cities. URBACT II Capitalisation, 6-9.

[6] Yasumoto, S., Jones, A.P., Nakaya, T., Yano, K. (2011). The use of a virtual city model for assessing equity in access to views. Computers Environment and Urban Systems, 35(6): 464-447. https://doi.org/10.1016/j.compenvurbsys.2011.07.002

[7] Charlton, J., Giddings, B., Thompson, E.M., Peverett, I. (2015). Understanding the interoperability of virtual city models in assessing the performance of city centre squares. Environment and Planning A, 47(6): 1298-1312. https://doi.org/10.1177/0308518X15594904

[8] Batty, M., Dodge, M., Doyle, S., Smith, A. (1998).
Visualising Virtual Urban Environments, CASA Working Paper 1. Centre for Advanced Spatial Analysis, University College London.

[9] Firmino, R.J. (2004). Building the virtual city: The dilemmas of integrating strategies for urban and electronic spaces. https://www.researchgate.net/publication/34736569

[10] Castells, M. (1989). The Informational City: Information Technology, Economic Restructuring, and the UrbanRegional Process. Oxford, Blackwell.

[11] Chan, C.S. (1997). Virtual reality in architectural design. Conference: Computer Aided Architectural Design Research in Asia (CAADRIA 97). https://www.researchgate.net/publication/272820335_V irtual_Reality_in_Architectural_Design.

[12] Foucault, M. (1984). Des espaces autres. Architecture, Movement, Continuité, 5: 46-49. https://foucault.info/documents/heterotopia/foucault.het eroTopia.fr/.

[13] Mahdalickova, E. (2011). En quête de nouvelles expériences: 1'architecture et le virtuel. Réel-Virtuel, $\mathrm{n}^{\circ} 2$, Virtualité et quotidienneté. http://194.199.196.168/gerphau/spip.php?article10.

[14] Durand, J.P. (1987). La Machine Universe: Creation, Cognition et Culture Informa Tique, 49-50. https://www.persee.fr/doc/homso_00184306_1987_num_85_3_2321.

[15] Horne, M. (2004). Visualisation of Martyr's Square, Beirut. Conference on Construction Applications of Virtual Reality, ADETTI/ISCTE, Lisbon.

[16] Jamei, E., Mortimer, M., Seyedmahmoudian, M., Horan, B., Stojcevski, A. (2017). Investigating the role of virtual reality in planning for sustainable smart cities. Sustainability, $9(11)$ : 2006. https://doi.org/10.3390/su9112006

[17] Anke, V.D. (2019). The use of virtual reality in urban planning. Review Paper on the (DIS) Advantages and a New Perspective for Future Research, 16-17.

[18] Gaitatzes, A., Christopoulos, D., Rousso, M. (2017). Virtual reality interfaces for the broad public: Advances in human computer interaction. The Proceedings of Human Computer Interaction, pp. 200-202.

[19] Dufillot, O. (2014). L'architecture virtuelle. In France. https://dumas.ccsd.cnrs.fr/dumas-01225109.

[20] Horne, M., Thompson, E.M., Podevyn, M. (2007). An overview of virtual city modelling: Emerging organisational issues. CUPUM '07 10th International Conference on Computers in Urban Planning and Urban Management.

https://www.researchgate.net/publication/30870893_An _overview_of_virtual_city_modelling_Emerging_organ isational_issues.

[21] Li, H., Zhang, J., Xia, L., Song, W., Bode, N.W. (2019). Comparing the route-choice behavior of pedestrians around obstacles in a virtual experiment and a field study. Transportation Research Part C: Emerging Technologies, 107: 120-136. https://doi.org/10.1016/j.trc.2019.08.012

[22] Historic St. Louis City Neighborhoods Using Cesium.js Technology. http://vcities.umsl.edu/Notes/VCProj.html, accessed on June 16, 2021.

[23] Schrotter, G., Hürzeler, C. (2020). The digital twin of the city of Zurich for urban planning. PFG-Journal of Photogrammetry, Remote Sensing and Geoinformation Science, 88(1): 99-112. https://doi.org/10.1007/s41064- 
020-00092-2

[24] Kim, S., Kim, D., Choi, S. (2020). CityCraft: 3D virtual city creation from a single image. The Visual Computer, 36(5): 911-924. https://doi.org/10.1007/s00371-01901701-x

[25] Mili. (2018). VR Helsinki https://www.traveldailymedia.com/visit-helsinki-fromthe-comfort-of-ones-own-sofa-with-vr-helsinki/, accessed on June 16, 2021.
[26] Al-Hinkawi, W.S., Zedan, S.K. (2021). Branding for cities: The case study of Baghdad. In IOP Conference Series: Earth and Environmental Science, 779(1): 012037.

1315/779/1/012037

[27] Helsinki Marketing. (2020). Virtual Helsinki. https://news.cision.com/helsinki-marketing/r/virtualhelsinki-platform-powers-gaming-inspired-virtual-mayday-concert--as-city-looks-to-the-futur,c3099591. 